\title{
Mentalidades e Imaginário: (des)continuidades ${ }^{1}$
}

\section{Mentality and Imaginary: (dis)continuities}

\author{
Mônica Maciel Vahl' \\ Marciele Agosta de Vasconcellos ${ }^{3}$
}

\begin{abstract}
Resumo
O presente artigo procura fazer um breve panorama da historiografia, centrando-se especialmente nas correntes denominadas de Escola dos Annales e de Nova História Cultural para, posteriormente, analisar, de forma mais detalhada, o desenvolvimento dos conceitos de mentalidades e de imaginário. Nessa perspectiva, busca-se demonstrar como os debates acerca das limitações e das contribuições do conceito de mentalidades contribuíram na elaboração de definições mais precisas no conceito de imaginário. Utilizamos como fundamentação para a discussão teórica as reflexões de Baczko (1985), Burke (1997, 2005), Chartier (1991, 2006, 2009), Ginzburg (2001, 2006), Hunt (1992), Le Goff (1976), Patalagean (1998) e Pesavento (1995, 2003).
\end{abstract}

Palavras-chave: Teoria da História. Mentalidades. Imaginário.

\section{Abstract}

This article aims to present a brief overview of historiography, focusing especially in the approaches called the Annales School and the New Cultural History to subsequently analyzes with more details the development of the concepts of mentality and imaginary. In this perspective, it intends to demonstrate how the debates about the limitations and contributions of the concept of mentality contributed to the elaboration of definitions more precise in the concept of imaginary. We used for the theory discussion the reflections of Baczko (1985), Burke (1997, 2005), Chartier (1991, 2006, 2009), Ginzburg (2001, 2006), Hunt (1992), Le Goff (1976), Patalagean (1998) and Pesavento (1995, 2003).

Keywords: Theory of History. Mentality. Imaginary.

\section{Considerações iniciais}

A partir da década de 1970 os estudos históricos passaram por um processo de significativo alargamento, no que tange aos objetos de pesquisa, às abordagens e às metodologias utilizadas. Essa transformação ocorreu, em grande medida, por meio das contribuições e questionamentos advindos da Escola dos Annales e,

\footnotetext{
1 Este trabalho foi desenvolvido no âmbito do Projeto de Ensino "Grupo de Estudos sobre Teorias da História" (ICH/UFPEL), coordenado pela Prof. ${ }^{a}$ Dr. ${ }^{a}$ Márcia Janete Espig.

${ }^{2}$ Universidade Federal de Pelotas. Mestranda do Programa de Pós-Graduação em Educação da Universidade Federal de Pelotas. E-mail: monicamvahl@gmail.com.

${ }^{3}$ Universidade Federal de Pelotas. Mestranda do Programa de Pós-Graduação em Ciências Sociais da Universidade Federal de Pelotas. E-mail: ciele.vasconcellos@gmail.com.
} 
posteriormente, pela influência dos estudos que engendram a chamada Nova História Cultural. O presente trabalho pretende explicitar essa modificação do campo histórico para contextualizar e caracterizar os conceitos de mentalidades e imaginário.

A história das mentalidades procurou, a partir de uma diversidade teórica e metodológica, compreender o funcionamento das estruturas mentais coletivas, na longa duração. Por outro lado, os estudos centrados no imaginário social buscavam abarcar uma dimensão simbólica da sociedade, as representações, os discursos e as práticas percebidas como produtoras de sentidos e identidades.

Para uma melhor compreensão, este texto foi organizado em três partes. A primeira parte aborda as principais correntes historiográficas ocidentais, com a finalidade de situar a emergência da Escola dos Analles e da Nova História Cultural. A segunda parte discute as propostas teóricas acerca dos conceitos de "mentalidades" e de "imaginário". Por fim, a terceira parte, ao destacar as características centrais desses conceitos, estabelece algumas semelhanças entre ambos, todavia, sem asseverar a sua correspondência.

\section{Os diferentes fazeres históricos}

A história exerceu durante muito tempo o papel de guardiã da memória coletiva, explicando o passado, em busca de um futuro prometido. Nas obras de Heródoto, Tucídides e Políbio a história como a "mestra da vida" exaltou os grandes homens, narrou os eventos importantes e as fantásticas batalhas. Na Idade Média, a reflexão sobre o passado se centrou nas linhagens da nobreza, sendo influenciada pelos dogmas cristãos que reuniam, concomitantemente, elementos sagrados e profanos. Em meados do século XV, como atentam Funari e Glaydson (2008), os escritores renascentistas passaram a assumir posturas mais racionais a partir da releitura dos trabalhos de gregos e de romanos.

Sob a influência da Reforma, despontou-se a necessidade da verificação da autenticidade de textos, principalmente, os medievais utilizados para a comprovação de alguns privilégios da Igreja. Isso propiciou um avanço na crítica dos documentos e o desenvolvimento de técnicas para a comprovação de sua veracidade, através de evidências materiais. Um marco desse período foi o estudo de Lorenzo Vala que, em 
1440, publicou uma análise sobre a chamada Constitutum Donatio Constantini uma declaração escrita que atestaria a doação de terras feita pelo imperador Constantino à Igreja, em 337. Lorenzo Vala demonstrou que o documento não poderia ter sido escrito na época alegada.

O movimento iluminista, que se desenvolveu em meados do século XVIII, prezava a manutenção permanente do caráter de dúvida e a laicização do saber em direção a um conhecimento racional. Diversos pensadores da época como Montesquieu (1689-1755), Jean-Jacques Rousseau (1712-1778) e Adam Smith (1723-1790) impulsionaram a difusão de um conhecimento crítico, nos campos político, econômico e social. A acentuação da laicização das opiniões e a contestação dos dogmas estabelecidos acabaram por opor a religião e o conhecimento científico.

Esse período foi marcado pela euforia, na concepção de um aperfeiçoamento humano constante, o que eventualmente levaria a uma situação de bem-estar geral. $\mathrm{O}$ conhecimento passou a ser visto como algo que existiria em algum lugar à parte do homem e que poderia ser alcançado com sucesso, se abordado de maneira objetiva e neutra. A história, cada vez mais, procurava se constituir como ciência, passando a cumprir funções cívicas e pedagógicas, e sendo muitas vezes utilizada na legitimação dos Estados Nacionais. Na busca por uma origem romântica da nação, os historiadores buscavam construir uma continuidade temporal e uma identidade que, em tese, permitiria que todos se sentissem "filhos" da mesma pátria.

No processo de criação de uma narrativa comemorativa da nacionalidade, feita principalmente para a instrução dos mais jovens, foram criadas as bibliotecas, os museus e os arquivos que resguardavam e divulgavam essa "memória". A noção de patrimônio público também começou a ser discutida, Tétart (2000) salienta, por exemplo, que o século dos enciclopedistas fomentou uma grande preocupação com a pedagogia cívica.

Em um primeiro momento, o desejo de construir a história sobre bases científicas fez com que o modelo de conhecimento adotado fosse o das ciências naturais, em direção a ruptura com a tradição literária e a rejeição da filosofia. As ideias e concepções progressivas da história de Conde de Saint-Simon (1760-1825) exerceram forte influência nas postulações do pensador francês Auguste Comte (1798-1857) sobre a existência de uma "Física Social" que, aos moldes das ciências 
exatas, ela seria capaz de determinar as leis estáticas e dinâmicas da sociedade. A filosofia da história de Comte, eclipsada em uma concepção evolutiva do progresso humano (estágios teleológico, metafísico e positivo), marcou a historiografia do século XIX.

Essa perspectiva estimulou uma valorização das fontes escritas, gerando uma febre documental e a publicação de um enorme volume de documentos, na perseguição de uma pretensa história completa e perfeita. Através do aperfeiçoamento da erudição crítica, o documento triunfou como sustentação de uma história que acreditava ser autêntica e verdadeira.

A busca da cientificidade na história, que refletia as concepções do pensamento racional-cartesiano, contribuiu para acentuar a crença no progresso linear da humanidade. Refletindo na produção historiográfica da época, o desenvolvimento de métodos e regras para a análise documental retrata a busca de um sujeito neutro, que visava aproximar a história da ciência e afastá-la da filosofia e da literatura.

Dessa forma, o historiador deveria se anular para fazer aparecer seu objeto, que se situava distante do presente, pois se acreditava que assim a especulação filosófica, a metafísica e a subjetividade teriam sido evitadas. Todavia, é importante destacar que Saliba (2009) afirma que muitos historiadores foram apressadamente e pejorativamente acusados de positivistas, tendo em vista que esse rótulo generalizante não privilegiou as dúvidas $e$ as oscilações presentes nos questionamentos e formulações de muitos historiadores do século XIX.

Nesse sentido, Burke (1997) atenta para as "vozes discordantes" na produção histórica dita positivista/metódica, no século XIX. Alguns autores, tais como Wihelm Dilthey passaram a defender a heterogeneidade entre as ciências naturais e humanas, outros como Jules Michelet e Jacob Burckhardt tinham uma visão mais ampla de história, interagindo com novas abordagens e criticando a suposição de que o historiador deveria ser um mero compilador de fatos.

Já Karl Marx dedicava à história um papel central para a transformação da realidade. Considerava que, através do estudo da vida material e concreta dos homens, seria possível o estabelecimento de leis estruturais e dinâmicas que explicariam o curso tomado por determinadas sociedades. Sugerindo que essas se 
modificariam a partir do conflito entre classes e das alterações nas forças produtivas. $^{4}$

O marxismo inaugurou, através da análise concreta da sociedade, as bases do chamado materialismo histórico. Para Reis (1999), o marxismo e a Escola Metódica, com suas próprias concepções e recusas às filosofias da história, confluem na busca de uma história científica. Além disso, Burke (1997, p. 19) considera que "Marx também oferecia um paradigma histórico alternativo [...] e, segundo sua visão histórica, as causas fundamentais da mudança deveriam ser encontradas nas tensões existentes no interior das estruturas socioeconômicas".

No inicio do século XX, a Escola dos Annales passou a defender uma história problema, ao invés da concepção tradicional de história factual, ampliando tanto a noção de fonte quanto a dos objetos de estudo. Ao propor uma relação de diálogo com outras disciplinas, como a geografia, a sociologia, a psicologia e a demografia, em um movimento de valorização da teoria e do sujeito conhecedor do passado, realizava nas palavras de Burke (1997) "uma revolução na historiografia".

Visando combater a história historicizante, que predominava na Europa, Marc Bloch e Lucien Febvre buscavam fomentar a inovação nas abordagens históricas e a aproximação com as demais disciplinas. Em 1929, publicaram a revista Annales d'histoire économique et sociale, ao lado de um grupo de colaboradores de diversas áreas das ciências sociais, com o intuito de incentivar o intercâmbio intelectual. O grupo de historiadores, inicialmente liderados por Bloch e Febvre, na construção de uma "nova história", engendram a chamada primeira geração dos Annales.

Fernand Braudel se caracteriza como o nome de destaque da segunda geração dos Annales. Em sua obra O Mediterrâneo aspirava atingir a chamada "história total", a longa duração com grande ênfase nos aspectos sociais, econômicos e geográficos. Esses fatores suscitaram a aproximação do marxismo na produção universitária francesa. O enfoque na abordagem do econômico e do social, de forma estruturalista e de longa duração, ocasionou o distanciamento com os estudos da mentalidade, estimulados na primeira geração. Contudo, Vainfas (1997) alerta que, posteriormente, a longa duração de Braudel seria um conceito

\footnotetext{
${ }^{4}$ Para uma maior discussão indicamos o livro "Um toque de clássicos: Durkheim, Marx, Weber", de Quintaneiro; Barbosa e Oliveira (1999).
} 
amplamente utilizado pela terceira geração dos Annales para explicar as mudanças lentas nas estruturas de crenças e de comportamentos.

A terceira geração se caracterizou por um período de fragmentação, em termos de objetos e de metodologias e nas suas "lideranças". O estímulo inicial de Bloch e Febvre à história das mentalidades, na primeira geração dos Annales, tornou-se, na década de 1960, o principal interesse dos historiadores. Pesquisadores como Emmanuel Le Roy Ladurie, Jacques Le Goff, Pierre Nora e Philippe Ariés, sob o signo da chamada Nova História, desenvolveram estudos centrados em temáticas inovadoras como a infância, o medo, a morte e o amor.

Logo após, em um período de incertezas e descrença no modelo racionalistacartesiano de interpretação da realidade, ocorreu uma alteração, no que concerne ao estatuto de conhecimento moderno, sendo a própria concepção de ciência questionada. As verdades absolutas e os modelos totalizadores atravessaram severas críticas, gerando um abalo na crença, em um progresso linear e contínuo, e criando um sentimento de transitoriedade e de finitude.

A partir da década de 1980 o campo histórico foi abalado por essas inquietações e pelas relações com outras áreas de conhecimento, o que permitiu que novas perspectivas fossem incorporadas, tanto em termos teóricos quanto metodológicos. Destaca-se a importância das reflexões de nomes como Marcel Mauss, Michel Foucault, Mikhail Bakhtin, Nobert Elias e Pierre Bourdieu. Nessa conjuntura, desenvolveu-se uma maneira particular de fazer história que, centrada nos aspectos culturais, propunha problematizar temáticas que eram, até então, entendidas como inerentes à condição humana.

A historiografia passou a produzir trabalhos com um enfoque diferenciado, que expandiam as explicações culturais para fenômenos entendidos anteriormente como de ordem política ou econômica. ${ }^{5}$ Revelando, portanto, uma nova maneira de fazer e principalmente de conceber a história. Burke (2005) salienta que, nesse cenário, a própria conceitualização de cultura sofreu uma drástica ampliação, que possibilitou a superação da polarização que existia entre cultura erudita e popular,

\footnotetext{
${ }^{5}$ Estudos de cunho historiográfico, que de alguma forma desprendiam atenção e esforço, para compreender os aspectos culturais, remontam a trabalhos como o Outono da Idade Média (1919), de Johan Huizinga, porém, esse interesse permaneceu marginal, em relação aos paradigmas de explicação dominante, que preferiam de uma maneira geral uma abordagem do econômico e do social de forma estruturalista e de longa duração (HUNT, 1992).
} 
sendo ainda desenvolvidas novas concepções, como a de circularidade cultural e a de pluralidade de práticas culturais.

Além disso, os interesses por questões inovadoras, a exemplo da história do livro e da leitura, foram se propagando progressivamente, principalmente, com o aprofundamento das relações com disciplinas como a antropologia, a linguística e a teoria literária. Essas características passaram a denominar um movimento intitulado "nova história cultural", ${ }^{6}$ que era, ao mesmo tempo, influenciado por diferentes correntes historiográficas como, por exemplo, a nova história francesa, os neomarxistas britânicos e a micro-história italiana.

Tratando dos caracteres que definem e unificam essa linha historiográfica, que abriga uma ampla variedade de opiniões, Espig (1998b) considera o privilégio dado aos estudos sobre a cultura em um conceito compreendido a partir das discussões da antropologia, o resgate da reflexão sobre a subjetividade e a crítica a algumas formas de cientificidade como os principais fatores de união. Além desses, Soihet (2003) lembra também que o grupo heterogêneo de pesquisadores da nova história cultural possui especial interesse pelas manifestações populares, pelo simbolismo da vida cotidiana e pelo informal.

Ao refletir sobre as práticas que caracterizariam essa corrente, Chartier (2006, p. 29) concluiu que, mais do que a semelhança dos objetos pesquisados, o que a definiria seria o método, até então, inédito de compreender as relações entre as formas simbólicas e o mundo social, que procurava não ignorar as escolhas conscientes ou inconscientes que determinam a construção da narrativa histórica. No entanto, o mesmo autor, ao tratar da relação entre história e ficção, esclarece que "a ficção é um discurso que informa do real mas não pretende representá-lo nem abonar-se nele, enquanto a história pretende dar uma representação adequada da realidade que foi e já não é" (CHARTIER, 2009, p. 24).

Em uma perspectiva aproximada, Pesavento (2003, p. 58, grifo nosso), ao comentar as mudanças epistemológicas em relação à Nova História Cultural, afirma que

\footnotetext{
${ }^{6}$ A expressão "Nova História Cultural" foi utilizada pela primeira vez por Hunt (1992) no livro "A nova história cultural".
} 
representação e imaginário, o retorno da narrativa, a entrada em cena da ficção e a ideia das sensibilidades levam os historiadores a repensar não só as possibilidades de acesso ao passado, na reconfiguração de uma temporalidade, como colocam em evidência a escrita da história e a leitura dos textos.

Entre as principais contribuições das pesquisas identificadas com a Nova História Cultural estariam o alargamento da definição de cultura, a procura por uma maior precisão teórica, que colaborou para a discussão e para o refinamento de conceitos, como os de prática, de apropriação, de representação e de imaginário, e a opção por um enfoque diferenciado, em relação ao processo de construção da escrita da história.

\section{Mentalidades e imaginário: (des)continuidades}

A Escola dos Annales instaurou as bases da chamada Nova História, contribuindo para a expansão dos estudos centrados nas mentalidades. O crescente interesse dos historiadores por temas situados no universo múltiplo e complexo da cultura e a variedade de enfoques utilizados suscitaram diversos problemas, em relação à história das mentalidades, especialmente, de cunho teórico como a imprecisão do conceito.

Os estudos sobre as mentalidades seriam delineados a partir de uma heterogeneidade teórica e metodológica. Seu recorte social procurava abranger o coletivo, em detrimento do pessoal e do particular. As mentalidades seriam um tipo de estrutura mental, compartilhada pelos atores sociais em contextos específicos. No que se refere ao campo de análise da história das mentalidades, pode-se perceber uma maior interdisciplinaridade, tanto com a antropologia quanto com a sociologia e com a psicologia. Le Goff (1976), em seu clássico texto "As mentalidades: uma história ambígua", ressalta a importância da aproximação da história com as demais ciências humanas e sociais.

$\mathrm{Na}$ elaboração de estudos sobre as mudanças ou permanências nos padrões de comportamento, hábitos e costumes na longa duração, a história das mentalidades utilizou em boa parte de seus estudos a quantificação como aporte. No entanto, esse traço não pode ser considerado universal. De acordo com Ginzburg (2006), os estudos sobre as mentalidades seriam distintos de outras correntes 
historiográficas, como a história das ideias ou a história da cultura, pela preocupação com os arcaísmos e com a irracionalidades, e apresentariam como características principais "a insistência nos elementos inertes, obscuros, inconscientes de uma determinada visão de mundo" (GINZBURG, 2006, p. 23).

Em relação à abordagem temporal, existiria uma inspiração braudeliana na história das mentalidades, que procurava estudar as continuidades das formas de pensar em um longo período de tempo. Ao tratar das consequências dessa escala temporal, na história das mentalidades, Espig (1998a, p. 158) destaca que "ao situar-se na longa duração, a história das mentalidades encontra sérias dificuldades para explicar períodos de mudanças rápidas - como, por exemplo, um momento de revolução ou de comoção das estruturas".

Entre as principais críticas ao conceito estão as extrapolações indevidas, as conclusões pouco sólidas e as dificuldades em considerar os atores sociais frente às estruturas, levando a uma passividade dos sujeitos. Alguns autores como Rojas (2007, p. 67) chegaram inclusive a afirmar que a história das mentalidades não apresentou qualquer princípio teórico ou metodológico definido e que, ao lado de alguns poucos trabalhos sérios, sua problemática e seus temas foram, de uma maneira geral, banais e sem relevância.

A partir da década de 1980, com o estremecimento dos esquemas gerais de interpretações e com a realização de uma série de embates teóricos acerca das mentalidades, o conceito começou a cair em desuso. Em outra direção, a temática do imaginário passou a suscitar vasto interesse pelas ciências humanas e sociais, de forma geral, e pelos integrantes da Nova História Cultural, em especial.

Os estudos sobre o imaginário permaneceram, durante muito tempo, relegados a uma posição secundária, sendo costumeiramente associados à falsidade, ao ilusório e ao erro por alguns autores. Barbier (1994), ao discutir o termo “imaginário", evidencia sua ampla significação, sendo algumas vezes definido como uma série de devaneios que procuram fugir do cotidiano, algo intangível em um mundo oposto à realidade ou um engodo para constituição da identidade.

O conceito de imaginário sofreu um processo de dissociação de seus significados tradicionais, consolidando-se como um das áreas mais férteis e de maior produção, no âmbito da historiografia contemporânea. As coisas ditas e pensadas, os discursos e as imagens fariam parte de uma dimensão simbólica e não 
poderiam mais ser considerados como meros espelhos distorcidos do real. Para Swain (1994), o imaginário abarcaria a linguagem, as representações, os símbolos, as crenças e os discursos, sendo um criador de sentidos, de identidades, de coerências e de incoerências.

Ao encontro dessa posição Espig (1998a) reflete que

\begin{abstract}
ao estabelecer uma "identidade" para a sociedade, bem como códigos de comportamento coletivamente aceitos, o imaginário assume uma realidade especifica, não podendo ser percebido tão somente como um tipo de "adorno" de relações econômicas, políticas, etc., como se essas fossem as únicas "reais". Referindo-se ao real, o imaginário social não será mero reflexo desse, mas sim um conjunto de reflexões elaboradas a partir de materiais tomados de aspectos simbólicos existentes em determinada sociedade ou grupo (ESPIG, 1998a, p. 162).
\end{abstract}

Ao tratar da utilização do campo conceitual do imaginário na história, Patlagean (1998, p. 292) afirma que o seu domínio seria composto pelo conjunto das representações que cada cultura ou que cada nível de uma sociedade complexa expressa através das práticas, dos ritos, dos conceitos e dos valores. Esse conjunto de representações estaria localizado junto ao território da experiência humana e revelaria a variabilidade do limite entre o real e o imaginário.

O verdadeiro e o ilusório estariam de certa maneira unidos no imaginário social, em um jogo dialético, nos sistemas de representações, inclusive as quimeras e os devaneios manifestariam imagens construídas, alimentadas e algumas vezes escondidas a respeito de si próprio. Dessa forma, o problema do verdadeiro e do falso do que foi imaginado é posto de lado, pois mais interessante para a história do que atribuir o estatuto de verídico é descobrir quais foram as condições que permitiram o desenvolvimento de uma "comunidade de imaginação" (BACKZO, 1985; ESPIG, 1998b).

O imaginário seria um fio condutor que se reportaria tanto a um mundo do prosaico e do cotidiano quanto a um mundo das utopias e das elaborações mentais sobre coisas que concretamente não existem, dessa maneira, ele remeteria ao mesmo tempo a vida e ao sonho, e em ambas as figurações construiria o que denominamos de real (PESAVENTO, 2003, p. 47). Dessa forma, como conjunto de representações que os homens constroem para conferir sentido ao real, poderia ele evocar outros significantes e significados que não os explícitos ou literais. 
Ao tratar do conceito de representação, Chartier (1991, p. 184) percebe duas famílias de acepções aparentemente diferentes e contraditórias. A primeira invoca uma ausência, e evocada como mediadora subentende uma separação entre o representante e o representado. A segunda sugere uma presença, que estabelece uma relação entre o signo visível e o referente significado, na apresentação de uma pessoa ou de um objeto.

Em outra perspectiva, Ginzburg (2001) afirma que o debate sobre o termo representação precisa ultrapassar o "aborrecido jogo de espelhos". Percebendo como o próprio processo de percepção do imago (como figura, ficção e talvez como abstração) é datado e permeado de múltiplos significados, e atentando para o fato de que a concepção de imagem no sentido atual começou a se desenvolver no período renascentista.

O imaginário se configura em um conjunto de formas discursivas e imagéticas, que pode tanto possibilitar a coesão quanto o conflito, pois através de sua rede simbólica cria ressonâncias ou desconstrói o horizonte das formações sociais, em um eterno processo de atualização e ressignificação. Nesse sentido, atua como forjador social de sentidos, que tanto pode fornecer suporte a estrutura de poder vigente como, ao contrário, agir como uma potente força de alteração da realidade. Em um sentido próximo, Swain (1994) defende que

o imaginário opera, portanto, em dois registros: o da paráfrase, a repetição do mesmo sob outro invólucro; e o da polissemia, na criação de novos sentidos, de um deslocamento de perspectivas que permite a implantação de novas práticas. Assim, o imaginário, em suas duas vertentes, reforça os sistemas vigentes/instituídos e ao mesmo tempo atua como poderosa corrente transformadora (SWAIN, 1994, p. 52).

O imaginário também poderia ser compreendido através de uma analogia com a física, conforme a dualidade onda/partícula do comportamento da luz. Portanto, ao mesmo tempo em que o imaginário se comportaria como fluxo particular, exteriorizando o real através do campo simbólico, ele seria a própria expressão do real em sua singularidade imaginativa (BARBIER, 1994, p. 22).

Os estudos sobre o imaginário não deveriam desconsiderar a intrínseca relação entre texto e contexto, para escapar da emboscada que procura hierarquizar, de forma inflexível, as práticas e as temporalidades. Além disso, é pertinente destacar que as pesquisas que envolvem o imaginário estão, ou ao

Cad. de Pesq. Interdisc. em Ci-s. Hum-s., Florianópolis, Santa Catarina, ISSN 1984-8951 v.15, n.106, p. 221-234 - jan./jun. 2014 
menos deveriam estar, a procura dos sentidos e das intenções, encobertos a primeira vista, portanto realizando um tipo de história "a contrapelo".

\section{Considerações finais}

Os conceitos promovem o entendimento dos pressupostos teóricos e auxiliam a análise documental. No entanto, conceitos ambíguos e/ou mal definidos induzem a uma carência teórica. Petersen (2003) alerta que o alargamento do leque temático geralmente não é acompanhado por um desenvolvimento metodológico e por uma reflexão teórica, o que levaria, muitas vezes, a uma "falsa interdisciplinaridade" e à construção de uma forma tradicional de história rotulada de nova.

O caráter amplo e pouco delimitado, que marcou a história das mentalidades, suscitou uma série de debates. Essas imprecisões e ambiguidades colaboraram para o desgaste do conceito, o que favoreceu o desenvolvimento de oposições e críticas severas. Os problemas conceituais, no âmbito da história das mentalidades, bem como a aproximação com a antropologia, suscitaram uma formulação mais refinada do conceito de imaginário.

Os estudos sobre as mentalidades se propunham a compreender a estrutura mental de uma sociedade durante um longo período de tempo, caracterizando os elementos comuns a todos os indivíduos. As pesquisas sobre o imaginário, diferentemente, têm como objeto o conjunto de representações de uma parcela da sociedade, seus discursos e imagens, expressos através de diferentes práticas.

O conceito de mentalidades, a par de suas contribuições, apresenta problemas, que, discutidos e expostos, encontram-se, em grande parte, superados nos debates sobre o imaginário, fato que, no entanto, não o torna imune a críticas. Dessa forma, o reconhecimento das fragilidades teóricas das pesquisas sobre mentalidades incorporou uma série de debates mais produtivos, no âmbito dos estudos sobre imaginário. Por fim, consideramos relevante salientar que a divergência de perspectivas, a revisão conceitual, e o debate teórico são imprescindíveis à construção do saber histórico e precisam ser estimulados. 


\section{Referências}

BARBIER, R. Sobre o Imaginário. Em Aberto. Brasília, ano 14, n. 61, p. 15-23, jan./mar. 1994.

BACZKO, B. A imaginação social. In: LEACH, E. et al. Anthropos-Homem. Lisboa: Imprensa Nacional; Casa da Moeda, 1985. p. 296-332.

BURKE, P. A revolução francesa da historiografia: a escola dos Annales (19291989). São Paulo: UNESP, 1997.

. O que é História Cultural? Rio de Janeiro: Jorge Zahar Editora, 2005.

CHARTIER, R. A história ou a leitura do tempo. Belo Horizonte: Autêntica, 2009.

. A nova história cultural existe? In: LOPES, A.; VELOSO, M.; PESAVENTO, S. (Org.). História e Linguagens: texto, imagem, oralidade e representações. Rio de Janeiro: 7 Letras, 2006. p. 29-43.

5, p. 173-191. 1991.

. O Mundo como Representação. Estudos Avançados, São Paulo, v. 11, n.

COMTE, A. (1798-1857) Primeiras Lições. In: Os Pensadores. São Paulo: Abril Cultural, 1983, p. VII a XVI; 03-20.

ESPIG, M. Ideologia, mentalidades e imaginário: cruzamentos e aproximações teóricas. Revista Anos 90, Porto Alegre, n. 10, p. 151-167, 1998a.

. Limites e possibilidades de uma nova história cultural. Locus, Juiz de Fora, v. 4, n. 1, p. 7-18, 1998b.

FUNARI, P. P.; GLAYDSON, J. S. Teoria da História. São Paulo: Brasiliense, 2008.

GINZBURG, C. O queijo e os vermes: o cotidiano e as ideias de um moleiro perseguido pela Inquisição. São Paulo: Companhia das Letras, 2006.

. Representação: A palavra, a ideia, a coisa. In: GINZBURG, C. Olhos de madeira: nove reflexões sobre a distância. São Paulo: Companhia das Letras, 2001. p. 85-103.

HUNT, L. História, Cultura e Texto. In: HUNT, L. (Org.). A nova história cultural. São Paulo: Martins Fontes, 1992. p. 1-29.

LE GOFF, J. As mentalidades: uma história ambígua. In: LE GOFF, J.; NORA, P. (Orgs.). História: novos objetos. Rio de Janeiro: Francisco Alves, 1976. p. 68-83.

PATALAGEAN, E. A história do imaginário. In: LE GOFF, J. (Org.). A história nova. 4. ed. São Paulo: Martins Fontes, 1998. p. 291-316. 
PETERSEN, S. O pensamento histórico brasileiro: relações com as vertentes europeias e americanas, tendências e temáticas recente. História em Revista, Pelotas, v. 9, p. 07-43, 2003.

PESAVENTO, S. Em busca de uma outra história: imaginando o imaginário. Revista Brasileira de História, São Paulo, v. 15, n. 29, p. 9-27, 1995.

. História \& história cultural. Belo Horizonte: Autentica, 2003.

REIS, J. C. A História, entre a Filosofia e a Ciência. 2. ed. São Paulo: Ática, 1999.

ROJAS, A. Antimanual do historiador. Londrina: EDUEL, 2007.

SALIBA, E. T. Aventuras modernas e desventuras pós-modernas. In: PINSKY, C. B.; LUCA, T. R. (Orgs.). O Historiador e suas fontes. São Paulo: Contexto, 2009. p. 309-328.

SOIHET, R. Introdução. In: ABREU, M. e SOIHET, R. Ensino de História: conceitos, temáticas e metodologias. Rio de Janeiro: Casa da Palavra, 2003.

SWAIN, T. N. Você disse imaginário? In: SWAIN, T. N. (Org.). História no plural. Brasília: Ed. UnB, 1994. p. 43-67.

TÉTART, P. Pequena história dos historiadores. Tradução Maria Leonor Loureiro. Bauru, SP: EDUSC, 2000.

VAINFAS, R. História das mentalidades e História Cultural. In: CARDOSO, C.; VAINFAS, R. (Orgs.). Domínios da História: ensaios de teoria e metodologia. Rio de Janeiro: Campas, 1997. p. 127-162.

Artigo:

Recebido em: 01/07/2013

Aceito em: 13/06/2014 